\title{
Study of the Relationship between Parental Aggression and Family Health at National (Melli) Bank staffs, City of Rasht, Guilan Province, Iran
}

\author{
Abbas Sadeghi \\ Associate Professor, University of Guilan, Rasht City, Iran \\ Asadeghi_2003@yahoo.com \\ Nader Ofoghi \\ Assistant Professor, University of Guilan, Rasht City, Iran \\ n_ofoghi@yahoo.com \\ Maryam Babaei \\ B.A Counselling Student, University of Guilan, Rasht City, Iran \\ Maryamb1493@gmail.com
}

\section{Doi:10.5901/jesr.2015.v5n2p291}

\section{Abstract}

The purpose of this research was the study of the relationship between of parental aggression and their family health on National (Melli) Bank of Rasht city. Statistic society of this research included all National (Melli) Bank staff of Rasht city, that with regard to statistic mass(531)based on Kerjeci and Morgan formula(1970)first 22branches were selected by clustering sampling method and then based on emergence of sample200questionnaries were distributed and completed. Questionnaire data collection device have been aggression evaluation and family action. According to findings of this study, there is a direct relationship between factors of parental aggression (such as, physical aggression, word aggression, age, and enmity) and family health. That is with reduction of aggression in parents, their family health will be increased. Also there is a direct relationship between parental aggression and factors of family health (include: problem solving, roles, companion, relationship, emotional mixture, control of behavior) ( $p<0 / 01)$. Also there is a meaningful relationship between parental aggression and family health from age and number of children viewpoint, but there is a meaningful relationship from gender and educational level.

Keywords: aggression, family health, staff

\section{Introduction}

Family is the base of mass human society and it has an important stability and social individual growth. Attempt to family stability and its health, provides health base and general felicity. In its definition we should say that: family is a group of individuals who have relationship through blood, marriage and or breeding and live together during an unclear time.(Koen.1996,translator:Salasi).Islam defines the family as a group of persons who have civil ,legal and moral character which its primary center is formed from legal marriage of woman and man and is established through matrimony of couple. By connecting family member together each of them will have responsibility, law, and new task based on law.(Porrahim.2013)

Family is a social organization that its interpersonal relationship is the most important formation component of this organization. The type of relationship which exists between each of family member creates an atmosphere that produces emotion, feelings, thoughts, and behaviors and effects on family relationship, respectively. In the other words, form of relation makes the behaviors and behaviors make the relations, respectively. So for the correct understanding of constructs and process on family, from one side interpersonal relationships should be analyzed and from other side members behavior within family should be researched. Attention to family members behavior, without regarding to exist relationship in life environment, will create an unreal recognition of family.(Ahmadi.2011).Family is one the strongest social relation union and its different dimensions such as number of family members, education, income, power construct and family members solidarity are happiness determiners.(Arggyel.2001).

Family action, is the family capability in uniformity and or accordance with created changes during life, solving 
the confliction and aggression ,family members solidarity and success in discipline patterns, preserving the limitations and obeying rules and its principals is with the aim of protecting whole system(Portez and colleagues,1992).The researches have shown that there is a relationship between family performance and mental health and in families that relationship between members and family interaction is stable based on close relationship ,intimacy and interpersonal mutual understanding ,almost all members are resistant and immune against life pressures.(Sharef,2008).In addition, family performance is a stable predicator criterion for mental health.(Foroyande.2013)

In health systems of family, roles are also health and follow parents' behavior. Parents play the role of teachers, devote time to their children, pay attention to them and direct them. In health systems of family, roles are flexible and changeable. Movement is slow and gentle; they exchange their thought and have moderate relationship. Existence of three main factors calmness (solace), amity (pure love and without outlook) and mercy (kindness and affability) in each family are good symbols of its base structure. For this reason in each family which these three main and vital factors exist, there isn't any disorder (Ansari Jafari .2007). One of determiner factor in improving family condition based on Sater's opinion is relationship. Some of solidarity factors of family directly and some indirectly has effective role in improving relationship (Birjandi. 2011). Health and successful family is a series which all members are successful and all decorum of them has natural and successful procedure. This family member can use their human powers. They use these powers for communication and meet individual and group requirements. Health family is a health social in which people have health growth and people become mature.(Medical Science University, Khorasan. 2011).

Family and how they have relationship and manner of parents' relationship with children in formation of character, growth recognition, social and emotional of children has significant role. If nurturing method of parents is based on kindness and intimacy, it guarantees mental, growth recognition and social health of children.(Cheng,2008).Most psychologist without regarding to school which they behave in it, consider mutual interaction among parents and children as a base of child growth (Danesh and et al. 2014). Berenji and et al (2010) in a longitudinal study during two years have found that the more quality of parents relationship decreases, depression symptoms in them will increase. 2010). Within each family there are behaviors such as attention, showing love, devotion, sacrifice, aggression and anger, sulk, insolence, and scorn exist and sometimes, we see them. Existence of these behaviors are not alone indicator of existing relationship of family but relationship within family is result of interaction between two persons. (Ahmadi,2011).Health family provides the needs beyond its members such as home, food, education, and even physical and gender secure. Family members especially children need pat, hug, being heard and attention and therefore "natural and good" words which are used as a habit don't indicate family health. So, it is more suitable to use"health or unhealthy "words for describing family. (Medical Science University, Khorasan, 2011). Efficient family is a family which is able to supply emotional, mental and Physiological needs of its members (Lashkari, 2004 quoted from Ghamari and Khoshnam, 2011).

Researchers have shown that there is a negative and meaningful correlation between family performance and mental needs, latitude and competence in a way that the pore family performance, the les mental needs of members are met and the more out family relationship will exist. Also children are impressed by parents incompatibility and rough atmosphere of family; in a way that if family doesn't do its task, mental health of children, verbal and non-verbal communication of members, behavior al patterns and finally their conformity with member rules will be damaged (Ansari Jafari,2007). Existence of accordance in family also effects on its health. Family accordance is defined as extent which family system applies changes in inner functions (behaviors, rules, roles, and perceptions) and or outer facts for achieving to environmental compatibility. (Hekbara, Paukf, Felez, 2011).Another effective factor on family health is existence4 of moderate activities of leisure time. These activities are traveling in holiday, activities out of home or firm in cultural and sport events.(Smith and colleagues,2010).Variables which seem has relationship with family health performance is amount of parental aggression. Researchers have shown that there is direct relationship between family performance and willingness to adolescence aggression. That is, incompatibility and parent divorce has negative effects on physical, emotional and educational compatibility. Arbitrary nurturing methods and negligence and inattention of parents, both of them are effective in adolescence tendency toward guilt. (Ansarijafari,2007).parent s behavior in family is the most effective factor on their children condition. In most cases parents behavior is aggression together or with children and this way of behavior can make undesirable backwash such as attention disorder and anxiety in children (Vitolo and et.al). From other side, home aggression and anger is global problem that threats to damage family status and society and individual health and harm many others and have physical ,gender, and mental problems.(Sajadifar,2002).This anger happens in private context and usually woman and children are the first victims if it (Sandiyari and Emamipoor 2003,quoted from Yaghoobidoost, 2013). One of the home angers is spouse nuisance which include physical, gender, and emotional bad behaviors which usually are used to apply mastery and their power stability 
toward woman and other family member (Anderson and Lee2010).Other studies in this case are shown that there is a separation from parents and undesirable relationship with children and negative relationship with extent of depression and aggressive behaviors of children.(Marsh and Barber,2001).

Some psychologists know the regression as a behavior that damage others or potentially damage them. This damage can be physical such as smack and bite or verbal such as insult and scream and or legal such as grabbing by force.(Masen and collegues,2011,translator:Yasaei).Another definition of aggression emphasizes on intention of aggression and aggression is known as a behavior that happens to damage or nuisance others. Most researches have accepted a mixture of these definitions and behaviors which cause damage of others know aggressively, especially if the person knows his/her action damage others.(district cooperation office and university;1996). Froyd knows the aggression like libido as an inescapable nature of human.(Sholtez,2012,translator;SeyedMohammadi).According to Bandora, aggression like types of social behaviors is teachable. Human aren't born congenitally with aggressively responses, but they acquire these responses with different topics and exactly like they learn social; behaviors and learn this action directly as an experience and or through observing others behaviors.(Bondara,1990).Bu t the best and comprehensive definition of aggression is Brown's definition. He knows the aggression as any kind of action and behavior that are applied directly for damaging others who aren't intended to be damaged. Also aggression can be known as any behavior that damages, threats, or victim other person.(Sadeghi, Haghighi, 2006).

Researchers have shown that boys are more aggressive than girls. T his difference is seen in most cultures and almost in all boys. Boys have more physical and verbal aggression than girls (Mack Koy and Jacklean, 1974-1980, Park and Slabi 1983). From the second year of life these differences will appear. According to observed studies about toddlers between ages of 1 to 3 years, gender differences from the number off aggressions after 18 months are appeared and before it there isn't any sign of it.(Fagot and Hagan ,1982). Boys especially when they are offended or somebody intrudes into their works, they retaliate. In an observed study about children before school, boys were offended a little more than girls, but twice of girls retaliated. (Quoted from Park, Salaei, 1983).Social experience of boys and girls from aggression aspect is completely different. Aggression is a part of behavioral frame of men and essentially aggressively behavior is expected from boys and gradually is encouraged (Masen and et.al, 2011, translator: Yasaei). But it is important to attention to this point that although women and girls get mad soon but in comparison with men, less do aggressively behaviors and for this purpose show more tolerance (Feize Kashani, 1988). Also it should be proposed that one of the most important factors of individual differences is the age of people (Matus, and et al, 2010).

Many of done studies indicate that adolescences and adult who is aggressor, they have encountered much aggression during childhood and have known this action as a proper behavior in their mind. For this reason punishment is an increasing and encouraging factor of aggression: because in addition to cause anger and probably child aggression the person who punishes is also improper sample for child aggression (Akbari, 2011)

Parents who annoy children they had frequently been sacrificed to gender and physical abuse during childhood and stressful life condition has increased the amount of stress in unreliable families and increases probability of harsh behavior and neglect children.(Kaplan and Saduk, 2003, quoted from Yaghoobidoost,2013). Descriptive studies of Yang (1994) and Jill (1970) have shown that parents who annoy children don't get involve in social activities and receive less support from family and friends (Yaghoobidoost, 2013).

Children whom their parents are aggressor is more vulnerable: These kinds of children are more sad and angry: happiness and alacrity in these children in comparison to children, who don't have aggressor parents, are less. More important issue is the effect which children learn from aggressively behaviors of their parents. Researchers have shown that most aggressively actions happen at homes. According to statistic, More than 40\%percent of slain are killed in their life place and $1 / 4$ of all killers have blood relation with their slain and 1/2 of them is related to women and husbands. (Sadeghi , Haghighi, 2006)

With regard to above proposed materials that indicate the importance of surveying relationship between these variables, the purpose of this research is to investigate the relationship of parental aggression with their family health in National (Melli) Bank staff of Rasht City.

\section{Hypotheses and Research Questions}

The hypotheses of the study were:

First hypothesis: There is a relationship between parental aggressionfactors (physical aggression, verbal aggression, anger and enmity) and family health.

Second hypothesis: There is a relationship between parental aggression and family health (problem solving, roles, 
emotional companion, emotional mixture and control of behavior).

Third hypothesis: There is a relationship between family health factors and parental physical aggression.

Fourth hypothesis: There is relationship between family health factors and parental verbal aggression.

Fifth hypothesis: There is a relationship between family health factors and parents anger.

Sixth hypothesis: There is relationship between family health factors and parents enmity.

Also in this study we have surveyed following questions:

First question: Is there any difference among National (Melli) Bank staff of Rasht in relationship with amount of parental aggression on family health from age viewpoint?

Second question: Is there any difference among National (Melli) Bank staff of Rasht inrelation with amount of parents on family health from gender viewpoint?

Third question: Is there any differences among National (Melli) Bank staff of Rasht in relation with amount of parental aggression on family health from the number of children viewpoint?

Fourth question: Is there any differences among National (Melli) Bank staff of Rasht in relation with parental aggression on family health from education degree viewpoint?

\section{Research Method}

This research is a description of correlation or accordance type which is codified for evaluating relationship between two variables (parental aggression and family health). Statistic society of this research includes all National (Melli) Bank staff of Rasht in 2014. Sampling in this research had been done through clustering, classical method and finally based on sample appearance. That is, first two west and central areas of Rasht National (Melli) Bank were selected through clustering method. In the next step the branches were determined through classical sampling method, in these two areas. Finally 200 staff of National (Melli) Bank was selected to participate in research. A criterion for selecting sample volume is Kerjeci and Morgan (1970) table. Data collection was done by two questionnaires which totally had 89 materials (rules). 29rules wee related to evaluation of aggression questionnaire and 60 rules were related to family performance questionnaire (FAD).

Family performance questionnaire has been based on model and for the first time it has been used by Nigerian in Iran in 1995 and it has 60 questions which consider small scales of roles of, problem solving, relation, emotional companion, emotional mixture and control of behavior. For gaining scores, six scales are calculated so low scores indicate healthier performance and vice versa. Perpetuity of this questionnaire has been reevaluated and was calculated based on amount of a Alfa coefficient. Finally perpetuity of above questionnaire was approved.

New version of aggression questionnaire was reviewed by Bus and Parei (1992) which its previous version was called enmity questionnaire. This questionnaire is a self-report device which has 29 terms and four sub-scales, that is physical aggression, verbal aggression, anger and enmity.

Perpetuity of this questionnaire was reviewed and was calculated based on amount of Alfa coefficient. Finally perpetuity of this questionnaire was approved with high performance.

\section{Findings and Discussion}

Table 1: Mean and standard deviation of researched variables

\begin{tabular}{llcc}
\hline & Mean & standard deviation & number \\
\hline Family health & $2 / 08$ & $0 / 250$ & 200 \\
Aggression & $2 / 60$ & $0 / 557$ & 200 \\
Enmity & $2 / 66$ & $0 / 642$ & 200 \\
Verbal aggression & $2 / 72$ & $0 / 578$ & 200 \\
Physical aggression $2 / 41$ & $0 / 672$ & 200 \\
\hline
\end{tabular}

With regard to following table, with $99 \%$ confidence we can say that there is a direct relationship between factors of parental aggression and family health. That is with decreasing aggression, family health will increase. 
Table 2: Pearson correlation test in surveying variables

\begin{tabular}{lccccc}
\hline Family health & 1 & & & & \\
\hline Aggression & $* * 0 / 459$ & 1 & & & \\
Enmity & $* * 0 / 453$ & $* * 0 / 846$ & 1 & & \\
Anger & $* * 0 / 327$ & $* * 0 / 864$ & $* * 0 / 619$ & 1 & \\
Verbal aggression & $* * 0 / 332$ & $* * 0 / 743$ & $* * 0 / 578$ & $* * 5 / 27$ & 1 \\
Physical aggression & $* * 0 / 417$ & $* * 02 / 876$ & $* * 0 / 616$ & $* * 0 / 673$ & $* * 0 / 579$ \\
\hline
\end{tabular}

According to coefficient it is determined that remained predictions and Regression equation that is aggression and anger together can make clear about (0/23) of changes in criteria variables (family health).

Table 3: Mean and standard deviation of researched variable

\begin{tabular}{lccc}
\hline & Mean & standard deviation & number \\
\hline Aggression & $2 / 60$ & $0 / 557$ & 200 \\
Problem solving & $2 / 03$ & $0 / 324$ & 200 \\
Roles & $2 / 07$ & $0 / 292$ & 200 \\
Emotional companion $2 / 24$ & $0 / 303$ & 200 \\
Emotional mixture & $2 / 006$ & $0 / 320$ & 200 \\
Relation & $2 / 23$ & $0 / 322$ & 200 \\
Control of behavior & $1 / 98$ & $0 / 327$ & 200 \\
\hline
\end{tabular}

With 99\%confidence we can say that there is a direct relationship between parental aggression and family health.

Table 4: Pearson correlation test in surveying variables

\begin{tabular}{lllllll}
\hline Aggression & 1 & & & & & \\
Problem solving & $* * 0 / 174$ & 1 & & & & \\
Roles & $* * 0 / 194$ & $* * 0 / 365$ & 1 & & & \\
Emotional companion & $* * 0 / 454$ & $* * 0 / 251$ & $* * 0 / 338$ & 1 & & \\
Relation & $* * 0 / 383$ & $* * 0 / 518$ & $* * 0 / 4$ & $* * 0 / 454$ & 1 & \\
Emotional mixture & $* * 0 / 411$ & $* * 0 / 464$ & $* * 0 / 31$ & $* * 0 / 558$ & $* * 0 / 479$ & 1 \\
Control of behavior & $* * 0 / 388$ & $* * 0 / 607$ & $* * 0 / 514$ & $* * 0 / 489$ & $* * 0 / 700$ & $* * 0 / 615$ \\
\hline
\end{tabular}

Table 5: Mean and standard deviation of researched variables

\begin{tabular}{llcc}
\hline & Mean & standard deviation & number \\
\hline Physical aggression & $2 / 41$ & $0 / 627$ & 200 \\
Problem solving & $2 / 03$ & $0 / 324$ & 200 \\
Roles & $2 / 07$ & $0 / 292$ & 200 \\
Emotional companion & $2 / 24$ & $0 / 303$ & 200 \\
Relation & $2 / 006$ & $0 / 320$ & 200 \\
Emotional mixture & $2 / 23$ & $0 / 322$ & 200 \\
Control of behavior & $1 / 98$ & $0 / 327$ & 200 \\
\hline
\end{tabular}

With99\%confidence we can say that there is a direct relationship between factors of family health and parental aggression.

Table 6: Pearson correlation test in surveying variables

\begin{tabular}{|c|c|c|c|c|c|c|}
\hline Physical aggression & 1 & & & & & \\
\hline Problem solving & $* 0 / 157$ & 1 & & & & \\
\hline Roles & $* 0 / 196$ & $* * 0 / 365$ & 1 & & & \\
\hline Emotional companion & $* * 0 / 377$ & $* * 0 / 251$ & $* * 0 / 338$ & 1 & & \\
\hline $\begin{array}{l}\text { Relation } \\
\text { Ply }\end{array}$ & $* 0 / 331$ & $* * 0 / 518$ & $* * 00 / 482$ & $* * 0 / 454$ & 1 & \\
\hline Emotional mixture & $* 0 / 394$ & $* * 0 / 464$ & $* * 0 / 317$ & $* * 0 / 558$ & $* * 0 / 479$ & 1 \\
\hline Control of behavior & $* * 0 / 343$ & $* * 0 / 607$ & $* * 0 / 514$ & $* * 0 / 494$ & $* * 0 / 700$ & $* * 0 / 615$ \\
\hline
\end{tabular}


According to determine coefficient it will be clear that remained predictions and Regression equation that is emotional companion and emotional mixture together can make clear about(0/18) of changes of criterion variables(physical aggression).

Table 7: Mean and standard deviation of researched variables

\begin{tabular}{lccc}
\hline & Mean & standard deviation & number \\
\hline Physical aggression & $2 / 72$ & $0 / 578$ & 200 \\
Problem solving & $2 / 03$ & $0 / 324$ & 200 \\
Roles & $2 / 07$ & $0 / 292$ & 200 \\
Emotional companion & $2 / 24$ & $0 / 303$ & 200 \\
Relation & $2 / 006$ & $0 / 320$ & 200 \\
Emotional mixture & $2 / 23$ & $0 / 322$ & 200 \\
Control of behavior & $1 / 98$ & $0 / 327$ & 200 \\
\hline
\end{tabular}

With99\% confidence we can say that there is a direct relationship between factors of family health (except: problem solving and relation) and verbal aggression of parents.

Table 8: Pearson correlation test in surveying variables

\begin{tabular}{|c|c|c|c|c|c|c|}
\hline Verbal aggression & 1 & & & & & \\
\hline Problem solving & $* * 0 / 099$ & & & & & \\
\hline Roles & $* * 0 / 086$ & $* * 0 / 365$ & 1 & & & \\
\hline Emotional companion & $* * 0 / 373$ & $* * 0 / 251$ & $* * 0 / 338$ & 1 & & \\
\hline Relation & $* * 0 / 297$ & $* * 0 / 518$ & $* * 0 / 482$ & $* * 0 / 454$ & 1 & \\
\hline Emotional mixture & $* * 0 / 328$ & $* * 0 / 464$ & $* * 0 / 317$ & $* * 0 / 558$ & $* * 0 / 479$ & 1 \\
\hline Control of behavior & $* * 0 / 310$ & $* * 0 / 607$ & $* * 0 / 514$ & $* * 0 / 494$ & $* * 0 / 700$ & $* * 0 / 615$ \\
\hline
\end{tabular}

According to determine coefficient it will be clear that remained predictions and Regression equation that is emotional companion and control of behavior together can make clear about(016)the changes of criterion variable(verbal aggression).

\begin{tabular}{llcc}
\hline & Mean & standard deviation & number \\
\hline Anger & $2 / 71$ & $0 / 783$ & 200 \\
Problem solving & $2 / 03$ & $0 / 324$ & 200 \\
Roles & $2 / 07$ & $0 / 292$ & 200 \\
Emotional companion & $2 / 24$ & $0 / 303$ & 200 \\
Relation & $2 / 006$ & $0 / 320$ & 200 \\
Emotional mixture & $2 / 23$ & $0 / 322$ & 200 \\
Control of behavior & $1 / 98$ & $0 / 327$ & 200 \\
\hline
\end{tabular}

With99\% confidence we can say that there is a direct relationship between factors of family health (except: problem solving) and anger of parents.

Table 10: Pearson correlation test in surveying variables

\begin{tabular}{llccccc}
\hline Anger & 1 & & & & & \\
Problem solving & $* * 0 / 095$ & 1 & & & & \\
Roles & $* 0 / 148$ & $* * 0 / 365$ & 1 & & & \\
Emotional companion & $* * 0 / 400$ & $* * 0 / 251$ & $* * 0 / 338$ & 1 & & \\
Relation & $* * 0 / 270$ & $* * 0 / 518$ & $* * 0 / 482$ & $* * 0 / 454$ & 1 & \\
Emotional mixture & $* * 0 / 256$ & $* * 0 / 464$ & $* * 0 / 317$ & $* * 0 / 558$ & $* * 0 / 479$ & 1 \\
Control of behavior & $* * 0 / 243$ & $* * 0 / 607$ & $* * 0 / 514$ & $* * 0 / 494$ & $* * 0 / 700$ & $* * 0 / 615$ \\
\hline
\end{tabular}

According to determine coefficient it will be clear that remained predictions and Regression equation that is emotional companion together can make clear about(016)of changes of criterion variable(anger). 
Table 11: Mean and standard deviation of researched variables

\begin{tabular}{llcc} 
& Mean & standard deviation & number \\
\hline Anger & $2 / 66$ & $0 / 642$ & 200 \\
Problem solving & $2 / 03$ & $0 / 324$ & 200 \\
Roles & $2 / 07$ & $0 / 292$ & 200 \\
Emotional companion & $2 / 24$ & $0 / 303$ & 200 \\
Relation & $2 / 006$ & $0 / 320$ & 200 \\
Emotional mixture & $2 / 23$ & $0 / 322$ & 200 \\
Control of behavior & $1 / 98$ & $0 / 327$ & 200 \\
\hline
\end{tabular}

With99\% confidence we can say that there is a direct relationship between factors of family health parental aggression.

Table 12: Pearson correlation test in surveying variables

\begin{tabular}{|c|c|c|c|c|c|c|}
\hline Anger & 1 & & & & & \\
\hline Problem solving & $* * 0 / 218$ & 1 & & & & \\
\hline Roles & $* * 0 / 197$ & $* * 0 / 3651$ & & & & \\
\hline Emotional companion & $* * 0 / 375$ & $* * 0 / 251$ & $* * 0 / 338$ & 1 & & \\
\hline Relation & $* * 0 / 386$ & $* * 0 / 518$ & $* * 0 / 482$ & $* * 0 / 454$ & 1 & \\
\hline Emotional mixture & $* * 0 / 404$ & $* * 0 / 464$ & $* * 0 / 317$ & $* * 0 / 558$ & $* * 0 / 479$ & 1 \\
\hline Control of behavior & $* * 0 / 410$ & $* * 0 / 607$ & $* * 0 / 514$ & $* * 0 / 494$ & $* * 0 / 700$ & $* * 0 / 615$ \\
\hline
\end{tabular}

According to determine coefficient it will be clear that remained predictions and Regression equation that is emotional companion together can make clear about(0/16)of changes of criterion variable(enmity

Also with $95 \%$ percent of confidence we can say that there is a meaningful relationship between linear structure (relationship between parental aggression and family health) among National (Melli) Bank staff of Rasht with regard to their age group. That is, aggression in age group of 30-34 is more than other groups and with the same style, family health is also lower. There is no meaningful difference between parental aggression among National (Melli) Bank man and woman staff. In the other words, the amount of this relation in two groups is almost same.

Test result of variance analysis also shows that there is a meaningful difference between number of children with factors of aggression and family health. That is, with increasing the number of children, the amount of aggression will increase and with the same amount family health will also decrease. From one side there is no meaningful difference between aggressions with family health with regard to education level of National (Melli) Bank staff. In the other words, the amount of this relation is same in different education level.

\section{Discussion and Conclusion}

The purpose of this research is to survey the relationship between parental aggression and family health in National (Melli) Bank staff of Rasht city. For this reason research hypotheses were studied through statistic test which their results have been shown in table.

First hypothesis: With regard to result of table number1 there is a direct and meaningful relationship between factors of parental aggression (include: physical aggression, verbal aggression, anger and enmity) and family health. That is with increase of aggression in parents, their family health will increase. Research results of Ahangranzabi and et al also show this fact, that the best method of nurturing children for decreasing aggression and its factors is democratic style, that is style (method) can be indicator of family health. This research findings are also in accordance with research findings of mental institute in state (U.S), Argiz and et al (2005), Angrist and et al (1996), Christopher and et al (1993), Small and Laster (1994), Wildrew and Rot (2002), Cotz and Gatman (1993) and Mash and Barber (2001)all say that democratic method of nurturing children (which indicate family health performance)causes decrease of aggression and its factors.

Second hypothesis: According to table number 3, there is direct relationship between parental aggression and factors of family health (such as, problem solving, roles, emotional companion, relation, emotional mixture and control of behavior). Researches of Yousliyani and colleagues also indicated positive and meaningful correlation between family performance in all aspects (problem solving, playing roles, emotional response, emotional mixture, control of behavior and general performance) with disciplinary desirable behavior(with regard to that aggression is an undesirable behavior). Also researches of Frouzandeh and et al showed that tensional events like improper behaviors of parents (as their aggression) causes some bad function on family performance. 
Also question number 1 and 3 were approved. So there was a meaningful relationship between National (Melli) Bank staff in relation with parental aggression and family health from age and number of children viewpoint. But there was no meaningful difference in question number2 and 4 among National (Melli) Bank staff in relation with parental aggression family health from gender and education level viewpoint.

Achieved results can indicate the emphasis of parental aggression effect on their family health and vice versa. Therefore it is recommended to families take some steps for controlling aggression to more health of their families and finally to society. Also findings of this research indicated that some National (Melli) Bank staff argued that the lack of balance and economic safety in society was the reason of stress and finally bad temper and aggression. Because some parts of these activities for controlling this case is directed toward responsible people.

Also it is recommended to National (Melli) Bank responsible people that, take some actions for improving this case with regard to suitable educational plans with presence of mental health specialist and eminent family consultants.

\section{References}

Ahangarm Anzabi, Ahad and et al (2011) Relationship of nurturing method of parents with regard to adolescence aggression of Shabester, researches magazine of recognition and behavioral science.

Ahmadi, Ali Asghar (2011) Psychology of relationship within family, Mehdi Rezaei press, Tehran, Iran.

Akbari, Aboughasem (2011) Adolescence and adult problems. Growth and Development Press, Tehran, Iran.

Anderson. M. L.\& Leigh. I. W. (2010). Internal consistency and factor structure of the revised conflict tactics scales in a sample of deaf female college students. Family Violence, 25, 475-483.

Ansari Jafari, Mohammad (2007) Health family. Farahang Andisheh Press, Tehran, Iran

Argyle, M. (2001). The Psychology of happiness. London: Rutledge.

Bandura, A (1990) Selective activation and disengagement of control. Journal of Social Sciences. issue, 46-27-46.

Birjandi, Seyed Mehdi (2011) Counseling and psychiatry of family with approach of Iranian culture. Arvaye Noor press, Tehran, Iran.

Branje, S. J. T., Hale, W. W., III, Frijns, T., \& Meeus, W. H. J (2010) Longitudinal Associations Between Perceived Parent-Child Relationship Quality and Depressive.

Chang, Foolad, Sheykholeslami, Raziyeh, Safari, Hajar(2008)family aspects with styles of adolescence identity. Summary of Articles of Third Pathologic Congress, Tehran, Iran.

Danesh, Smat, Maenavi Shad, Marjan, Khoshabi, Katayoun Hasanzadeh Tavakoli, Mohamadreza (2014) effects of anger level and nurturing methods of mothers of who have inability in learning and normal on self-thoughts of their children, Family research magazine.

FeizKashani, MolMohsen (1988) Almahjal Biza. Maktabol Sodoogh, Tehran, Iran

Frouzandeh, Nasrin and et al (2013) Comparison of family performance in mental patients with different diagnoses of bed rid. Behavioral Sscience Research Magazine.

Ghamari, Mohammad, Khoshnam, Amirhosein(2011) Surveying the relationship of main family performance and life quality within students. Family Research Magazine.

Hackbarth, M., Pavkov, T., \& Flannery, M. (2011).Natural Disasters: An Assessment of Family Resiliency Following Hurricane Katrina. Journal of Marital and Family Therapy, 37, $1-12$.

Koen, Bruc (1996) An introduction to society. Translation: Salasi, Mohsen Semat Press, Tehran, Iran.

Mars. J. Growert, Brian. K. (2001). Connectedness and separation in Parent adolescent ralationship .Indicators of a Successful Identity development? Paper presented at the Biennial Meeting of the Society for Research in Child Development.

Masen, Paual Henry and et al (1390) Characteristic growth of child. Translation: Yasaie, Mahshid, Mad Publications, Tehran, Iran.

Matthews, R. A., Bulger, C. A., \& Barnes-Farrell, J. L. (2010) Work social supports, role stressors, and work-family conflict: The moderating effect of age. Journal of Vocational Behavior, 76(1), 78-90.

Medical Science University and cure sanitary service of Khorasan (2011) Health family . Mashhad, Iran

District cooperation office and university (1996) Growth psychology attitude toward Islam resources, Tehran,. Iran.

Poor Rahimi, Mohammadreza.(2013) Family knowledge and population. Central Press of SloobElmi and Behshar ,.Iran

Portes P R, Howl SC, Brown JH, Eichenberger S, Mas CA (1992). Family functions and children post divorce adjustment. Am J Orthopsychiatry; 62(4): 613-7

Sadeghi, Abbas. Moshkbidi Haghighi, Mohsen.(2006) Aggression management. Haghshenas press. Rasht, Tehran

Sajadi Form, Z., and et al(2002) Investigating the frequency of physical violence against women during pregnancy and its relation with undesirable outcomes. PHD .leaft. Medical science university of Tehran

Sharf, R S. (2008). Theories of Psychotherapy counseling concepts and cases.4th ed. New York: The Guilford Press

Sholtez, Davan, Sholtez, SeydaniAlen, translation: Seyed Mohammadi, Yahya (2012) Characteristic theories Vivayesh Press, Tehran, Iran

Smith, K. M., Freeman, P. K., \&. Zabriskie. R. B. (2010). An Examination of Family Communication within the Core and Balance Model of Family Leisure Functioning. Family Relations, 58, $79-90$

Vitolo YL, Elitlich- Bilyk B, Goodman R, et al (2005). Parental Beliefs and child rearing attitudes and mental Health problems among school children, Revista de Saude publica; 39(5): 716- 24

Yaghoobiidoost, Mohammad (2013) Surveying the relation of social seclusion with amount of home rage of parents toward adolescence. Specific magazine of social science of Islamic Azad university of Shooshtar

Yousilani, GholamAli, Mojtaba, Soleimanbi, Esmaeil (2012) Relation of disciplinary desirable behavior with family performance, Psychology Magazine of School. 